Saudi Journal of Oral and Dental Research

Abbreviated Key Title: Saudi J Oral Dent Res

ISSN 2518-1300 (Print) |ISSN 2518-1297 (Online)

Scholars Middle East Publishers, Dubai, United Arab Emirates

Journal homepage: https://saudijournals.com/sjodr

\title{
Oral Health Related Quality of Life in Relation to Caries Experience
}

\author{
Dr. Monika ${ }^{1 *}$, Pradeep Tangade ${ }^{2}$, Vipul Yadav ${ }^{3}$, Hunny Sharma ${ }^{4}$, Yogesh garg ${ }^{5}$, Vinay Kalra ${ }^{6}$ \\ ${ }^{1}$ Senior Resident Department of Public Health Dentistry, PGIDS, Rohtak, Haryana, India \\ ${ }^{2}$ Prof \& Head Department of Public Health Dentistry, Teerthanker Mahaveer Dental College and Research Centre, Moradabad, Uttar Pradesh, India \\ ${ }^{3}$ Assistant Professor Department of Public Health Dentistry, PGIDS, Rohtak, Haryana, India \\ ${ }^{4}$ Senior lecturer Department of Public Health Dentistry, Treveni College of Dental sciences and Research, chattisgarh, India \\ ${ }^{5}$ Senior lecturer Department of Public Health Dentistry, Surendra Dental College and Research Center, Sriganganagar, Rajasthan, India \\ ${ }^{6} \mathrm{PG}$ Student MD Radiology, MOI University, Kenya
}

DOI: $10.36348 /$ sjodr.2020.v05i03.009

| Received: 03.03.2020 | Accepted: 15.03.2020 | Published: 21.03 .2020

*Corresponding author: Dr. Monika

\section{Abstract}

Background: Oral diseases are the most common chronic diseases having considerable impact on quality of life. Quality of life is the final goal in every child's development. Aim: The aim of the present study was to assess the oral health related quality of life (OHRQoL) of 12- 15 year old School going children of Moradabad City. Material and method: Study was conducted on 392, 12- 15 years old school going children in Moradabad city. The clinical examination was done by using WHO Oral Health Assessment Form for Children 2013. A child perception questionnaire by Jokovic et al was filled by the students and personal interview of parents was done to collect data regarding their oral health related quality of life. Result: Out of 392 subjects examined 207 (52.8\%) were caries free whereas 185 (42.7\%) subjects showed dental caries. Mean total DMFT was recorded as $1.14 \pm 1.70$. Mean total CPQ score at was recorded as $26.87 \pm 16.12$. Conclusion: Presence of dental caries was found to be associated with increased CPQ score presentation a positive impact on Quality of Life of children.

Keywords: Child Perception Questionnaire; Oral Health; Quality of life.

Copyright @ 2020: This is an open-access article distributed under the terms of the Creative Commons Attribution license which permits unrestricted use, distribution, and reproduction in any medium for non-commercial use (NonCommercial, or CC-BY-NC) provided the original author and source are credited.

\section{INTRODUCTION}

Oral diseases are the most common chronic diseases having considerable impact on quality of life. They are of considerable public health concern because of their prevalence, the high expense of their treatment and their impact on the individuals and society. The determinants of oral diseases are known. They are the risk factors common to a number of chronic diseases: Diet and dirt (hygiene), smoking, alcohol, risky behaviors causing injuries and stress. Although common oral diseases are not life threatening, their outcomes may influence the overall wellbeing of individuals and populations. Regardless of race, sex, geographic location, culture, oral diseases cause pain and suffering and effect the physical, mental, social and functional wellbeing of individuals $[1,2]$.

Quality of life is the final goal in every child's development. Health-related quality of life is placed under the umbrella of the general term 'quality of life' and is described as a complete physical, emotional, mental or psychological and social well-being rather than merely the absence of disease or infirmity [3].
Oral health-related quality of life is defined as an individual's assessment of how the following affect his or her wellbeing: functional factors, psychological factors, social factors, and experience of pain/discomfort in relation to orofacial concerns [4]. Many self- perception measurement instruments have been developed and include psychological and social aspects to measure oral health-related quality of life. Some instruments previously used for this purpose are the Oral Health Impact Profile (OHIP), Child Perceptions Questionnaire (CPQ 11-14), Early Childhood Oral Health Impact Scale (ECOHIS) and Child Oral Health Quality of Life (COHQoL) [5]. Earlier many studies have been conducted but, there is no data regarding OHRQoL of children in Moradabad City. Therefore, the aim of the present study was to measure the oral health related quality of life (OHRQoL) of 12- 15 year old School going children of Moradabad City. 


\section{MATERIAL AND METHOD}

This cross sectional study was conducted on a sample of 392, 12-15 years students from government and private schools of Moradabad city. Study group was selected using systematic randomized sampling. This sample size was calculated on the basis of dental caries prevalence recorded through a Pilot Survey. Prior to start of study Ethical Clearance was obtained from the Institutional Ethics Committee. Approval was taken from respective school authorities and informed consent was obtained from parents or Guardian of study subjects. The study was conducted in 4 Government and 4 Private schools of Moradabad, 49 students from each school were taken for uniform sampling. In order to have uniform assessment and minimum variability all the examinations were done by single examiner. Examiner and a recording clerk was trained and calibrated in the department before the commencement of study.

\section{Inclusion Criteria}

[a] Children who are permanent residents of Moradabad city.

[b] Children of 12 to 15 year old age group only.

[c] Children who were willing to participate.

\section{Exclusion Criteria}

[a] Children whose parents do not give informed consent.

[b] Children who are severely ill.

[c] Children who are undergoing or had already undergone any kind of orthodontic treatment.

The clinical examination was done by using WHO Oral Health Assessment Form for Children 2013 [6] and general information, dentition status, periodontal status, enamel fluorosis, dental erosion, dental trauma and intervention urgency was recorded. A type-III examination was conducted by single examiner in the premises of school. A child perception questionnaire by Jokovic et al. [7] was filled by the children to report their perception regarding their oral health related quality of life. CPQ 11-14 deals with the frequency of events happening during the previous 3 months and data regarding their socioeconomic status was recorded [8]. CPQ $11-14$ is a 37 items scale distributed amongst 4 domains:

1. Oral symptoms

2. Functional limitations

3. Emotional well-being and

4. Social well-being.

A 5-point Likert scale was used for computing by adding up all of the item scores under that domain 'never' $=0$, 'once/twice' $=1$, 'sometimes' $=2$, 'often' $=$ 3 , 'every day/almost every day' $=4$. The total CPQ score varies from 0 - 148, where a high score denotes an impact on QoL.
Data was entered in excel sheet using personal computer and Statistical package for social sciences (SPSS -20) was used for analysis of data. Results were considered to be statistically significant at $\mathrm{P}<0.05$.

\section{RESULTS}

This study was conducted to assess OHRQoL in $12-15$ years old school going children in Moradabad city, U.P. India. A total of 392 students, from government (group 1) and from private schools (group 2) were chosen.

According to age, out of 392 study subjects 200 were of 12 years of age that accounts to about $51 \%$ of the total sample. 122 subjects were from 13 years age group, 65 from 14 year and 5 from 15 years age group which makes it $31.1 \%, 16.6 \%$ and $1.3 \%$ respectively. According to gender, $255(65 \%)$ study subjects were males and 137(34.9\%) were females that constituted a total sample of 392 subjects. Frequency of oral problems as per WHO Form is reported by study subjects are shown in Table 1.

\section{Table-1: Frequency of oral problems present in} study subjects

\begin{tabular}{|l|l|}
\hline $\begin{array}{l}\text { Oral Problem } \\
\text { Present }\end{array}$ & Frequency \\
\hline Decayed teeth & $47.2 \%(185)$ \\
\hline Missing teeth & $0.8 \%(3)$ \\
\hline Filled teeth & $1.5 \%(6)$ \\
\hline Total DMFT & $47.4 \%(186)$ \\
\hline Gingival Bleeding & $25 \%(98)$ \\
\hline Dental Fluorosis & $0.5 \%(2)$ \\
\hline Dental Trauma & $0.8 \%(3)$ \\
\hline Intervention Urgency & $66.8 \%(262)$ \\
\hline
\end{tabular}

Out of 392 subjects examined 207 (52.8\%) were caries free and rest $185(42.7 \%)$ subjects had decayed tooth ranging from 1-11. In terms of highest score, 11 decayed teeth were recorded in $1(0.3 \%)$ subject whereas for lowest recordings 1 decayed tooth was recorded in $77(19.6 \%)$ study subjects. Mean total DMFT was recorded as $1.14 \pm 1.70 .294(75 \%)$ subjects were recorded with a gingival bleeding score 0 that implies the absence of gingival bleeding and only 98 $(25 \%)$ subjects were reported with gingival bleeding irrespective of site of bleeding (graph 1). Out of 392 subjects examined $130(33.2 \%)$ were recorded with an intervention urgency score 0 , only $4(1 \%)$ subjects were reported with intervention urgency score 1 and 258 $(65.8 \%)$ subjects were reported with intervention urgency score 2 . 
Monika et al; Saudi J Oral Dent Res, March 2020; 5(3): 184-188

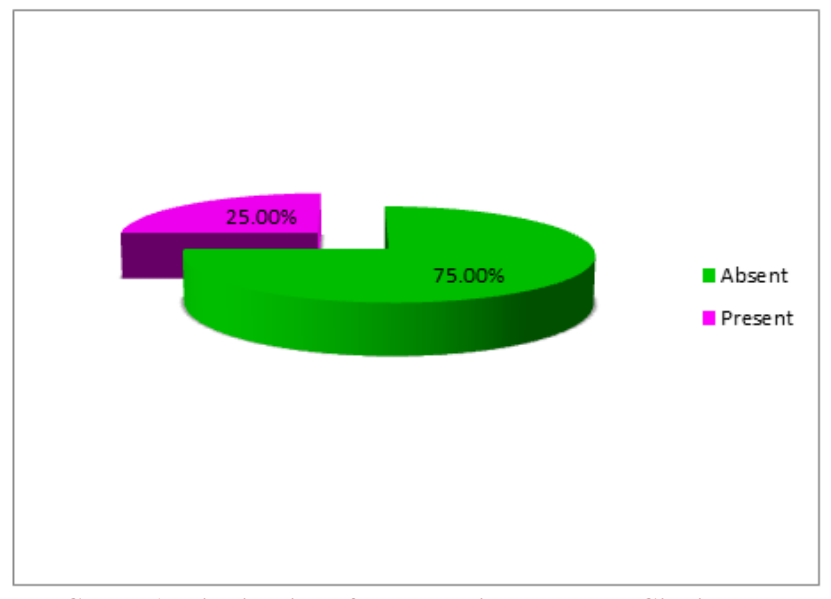

Graph-1: Distribution of study subject based on Gingival Bleeding
For group 1 and group 2, Mean DMFT scores were recorded as $1.45 \pm 1.8$ and $0.83 \pm 1.48$ respectively. For Mean DMFT according to gender in males and females was $1.04 \pm 1.70$ and $1.33 \pm 1.70$ respectively.

Distribution of Study Population Based on Global Rating Questions (Table 2)

Health of oral cavity

Regarding health of oral cavity, $8.2 \%$ of children rated their oral health as excellent.

\section{Extent to which oral health affects overall life}

Regarding extent to which oral health affects overall life, $16.8 \%$ reported it as not at all.

Table-2: Distribution of study population based on Global Rating Questions

\begin{tabular}{|l|l|l|l|}
\hline Health of oral cavity & Frequency $(\boldsymbol{\%})$ & Extent to which oral health affects overall life & Frequency (\%) \\
\hline Excellent & $32(8.2)$ & Not at all & $66(16.8)$ \\
\hline Very Good & $93(23.7)$ & Very Little & $104(26.5)$ \\
\hline Good & $185(47.2)$ & Some & $107(27.3)$ \\
\hline Fair & $64(16.3)$ & A Lot & $33(8.4)$ \\
\hline Poor & $18(4.6)$ & Very Much & $82(20.9)$ \\
\hline Total & $\mathbf{3 9 2}$ & Total & $\mathbf{3 9 2}$ \\
\hline
\end{tabular}

Child Perception Questionnaire Score (Table 3)

Mean total CPQ score was recorded as 26.87 \pm 16.12 . Mean CPQ score for individual domain was recorded and was found to be $4.56 \pm 3.34$ for oral symptoms, $7.46 \pm 4.90$ for functional limitation, $8.06 \pm$
5.35 emotional well-being and $6.79 \pm 6.23$ for social well-being. For total score according to gender in males and females was $26.66 \pm 17.25$ and $27.25 \pm 13.83$ respectively.

Table-3: Mean CPQ Score

\begin{tabular}{|l|l|l|l|}
\hline Domain & Mean \pm SD & SE & p-value \\
\hline Oral Symptoms & $4.56 \pm 3.34$ & .169 & $0.001^{*}$ \\
\hline Functional Limitation & $7.46 \pm 4.90$ & .248 & $0.001^{*}$ \\
\hline Emotional Well-being & $8.06 \pm 5.35$ & .270 & $0.001^{*}$ \\
\hline Social Well-being & $6.79 \pm 6.23$ & .315 & $0.001^{*}$ \\
\hline Total & $26.87 \pm 16.12$ & .814 & $0.001^{*}$ \\
\hline
\end{tabular}

Table 4 describes relative status between dental caries and CPQ Score in all four domains. An increase in CPQ Score was recorded with increase in DMFT Score. Overall CPQ Score and caries showed statistically significant results. $(\mathrm{p}=0.34)$ with a positive association in Social Wellbeing Domain was also recorded which signifies that presence of dental problems had a positive impact on social life of individuals.

Table-4: Dental Caries Status and CPQ Score

\begin{tabular}{|c|c|c|c|c|c|}
\hline Domain & $\begin{array}{l}\text { Oral symptoms } \\
\text { Mean } \pm \text { SD }\end{array}$ & $\begin{array}{l}\text { Functional } \\
\text { limitations } \\
\text { Mean } \pm \text { SD }\end{array}$ & $\begin{array}{l}\text { Emotional well- } \\
\text { being } \\
\text { Mean } \pm \text { SD }\end{array}$ & $\begin{array}{l}\text { Social } \\
\text { well-being } \\
\text { Mean } \pm \text { SD } \\
\end{array}$ & $\begin{array}{l}\text { Total CPQ } \\
\text { Score } \\
\text { Mean } \pm \text { SD }\end{array}$ \\
\hline 0 DMFT & $4.21 \pm 3.14$ & $7.27 \pm 5.03$ & $7.72 \pm 5.37$ & $6.35 \pm 5.89$ & $25.55 \pm 15.87$ \\
\hline 1-2 DMFT & $4.75 \pm 3.42$ & $7.22 \pm 4.68$ & $7.97 \pm 5.10$ & $6.79 \pm 6.13$ & $26.72 \pm 15.58$ \\
\hline 3-4 DMFT & $5.48 \pm 3.73$ & $8.76 \pm 4.98$ & $10.00 \pm 5.59$ & $9.33 \pm 7.63$ & $33.57 \pm 17.24$ \\
\hline$>5$ DMFT & $4.95 \pm 3.73$ & $8.14 \pm 4.43$ & $8.05 \pm 5.61$ & $6.05 \pm 6.20$ & $27.19 \pm 17.26$ \\
\hline F-value & 2.025 & 1.32 & 2.15 & 2.81 & 2.92 \\
\hline p-value & 0.110 & 0.26 & 0.09 & $0.039 *$ & $0.034 *$ \\
\hline
\end{tabular}




\section{DISCUSSION}

The importance of OHRQoL is particularly relevant for children as a number of their social and psychological coping skills are still developing. The purpose of this cross sectional study was to measure the oral health related quality of life (OHRQoL) of 12- 15 year old School going children of Moradabad City.

All over the world dental caries is the most common oral disease affecting children. In the present study dental caries was evident among $47.2 \%$ of the study subjects with the mean DMFT - 1.14 lower than the studies by Dhar V et al. [9], Goyal A et al. [10], and $\mathrm{J}$ Moses et al. [11] conducted in other parts of India. This decline in dental caries among the study population may be due to exposure to higher levels of fluoride in drinking water of these children.

CPQ 11-14 was used as instrument for measurement as Children's perspectives on the impact of oral health on their quality of life may differ from the views of their parents or guardians as parents may provide complementary information because they are closely involved with their children's health, including decision making. In the present study there is an increase in the CPQ overall score and the mean scores across various domains like 'oral symptoms', 'functional limitations', 'social well-being' and 'emotional well-being' with the increase in severity of dental caries. These results are in accordance with the study conducted by Loc DG et al. [12] and Vargas Ferreria et al. [13]. Caries experience was found to have a possible link to oral symptoms and functional Limitations, as dental caries can cause pain and discomfort affecting the functions like mastication and sometimes even being absent from the school.

According to group, group 2 children had a lower Mean DMFT and lower CPQ Score. As group 2 children belong to private school population with a higher socioeconomic status. So awareness and socioeconomic status can account for better oral health and perception towards quality of life. These results are in accordance with study conducted by Paula JC et al. [14].

Based on gender a lower Mean DMFT was recorded in females giving an account that females are more concerned about their oral health, general health and overall wellbeing. No such studies are found in literature regarding sex predilection of quality of life so no such comparisons can be done.

This study has few limitations to overcome; further studies can be done taking larger sample size and traumatic injuries in consideration as TDI may show more impact on quality of life of an individual.

\section{CONCLUSION}

In summary, having dental caries, dental fluorosis or dental calculus had negative effects on children's oral health-related quality of life. The children's self-reported CPQ 11-14 reports associations between their oral health status and CPQ Domains especially for social and emotional well-being

\section{REFERENCES}

1. Pentapati, K. C., Acharya, S., Bhat, M., Rao, S. V. K., \& Singh, S. (2013). Oral Health-related quality of life and associated factors in National Cadets Corps of Udupi District, India. World Journal of Dentistry, 4(2), 81-85.

2. Bhatti, M. U. D., Chaudhary, M. A., \& Bokhari, S. A. H. (2010). Self-reported impacts of oral health on quality of life amongst 11-14 years old school children of lahore, pakistan. Pakistan Oral \& Dental Journal, 30(1).

3. Krisdapong, S., Prasertsom, P., Rattanarangsima, K., Adulyanon, S., \& Sheiham, A. (2012). Using associations between oral diseases and oral healthrelated quality of life in a nationally representative sample to propose oral health goals for 12- yearold children in Thailand. International dental journal, 62(6), 320-330.

4. Fotedar, S., Sharma, K. R., Fotedar, V., Bhardwaj, V., Chauhan, A., \& Manchanda, K. (2014). Relationship between oral health status and oral health related quality of life in adults attending HP government dental college, Shimla, Himachal Pradesh-India. Oral Health Dent Manag, 13(3), 661-665.

5. Piovesan, C., Batista, A., Ferreira, F. V., \& Ardenghi, T. M. (2009). Oral health-related quality of life in children: Conceptual issues. Revista Odonto Ciencia, 24(1), 81-85.

6. Oral Health Survey Basic Method. (2013). $5^{\text {th }}$ Edition. World Health Organization, 85

7. Jokovic, A., Locker, D., Stephens, M., Kenny, D., Tompson, B., \& Guyatt, G. (2002). Validity and reliability of a questionnaire for measuring child oral-health-related quality of life. Journal of dental research, 81(7), 459-463.

8. Oberoi, S. S. (2015). Updating income ranges for Kuppuswamy's socio-economic status scale for the year 2014. Indian journal of public health, 59(2), 156.

9. Dhar, V., Jain, A., Van Dyke, T. E., \& Kohli, A. (2007). Prevalence of dental caries and treatment needs in the school-going children of rural areas in Udaipur district. Journal of Indian society of Pedodontics and Preventive dentistry, 25(3), 119.

10. Goyal, A., Gauba, K., Chawla, H. S., Kaur, M., \& Kapur, A. (2007). Epidemiology of dental caries in Chandigarh school children and trends over the last 25 years. Journal of Indian Society of Pedodontics and Preventive Dentistry, 25(3), 115. 
11. Moses, J., Rangeeth, B. N., \& Gurunathan, D. (2011). Prevalence of dental caries, socio-economic status and treatment needs among 5 to 15 year old school going children of Chidambaram. J Clin Diagn Res, 5(1), 146-51.

12. Do, L. G., \& Spencer, A. (2007). Oral healthrelated quality of life of children by dental caries and fluorosis experience. Journal of public health dentistry, 67(3), 132-139.

13. Vargas-Ferreira, F., \& Ardenghi, T. M. (2011). Developmental enamel defects and their impact on child oral health-related quality of life. Brazilian oral research, 25(6), 531-537.

14. Paula, J. S., Leite, I. C., Almeida, A. B., Ambrosano, G. M., Pereira, A. C., \& Mialhe, F. L. (2012). The influence of oral health conditions, socioeconomic status and home environment factors on schoolchildren's self-perception of quality of life. Health and quality of life outcomes, 10(1), 6. 